\title{
Municipal Crossing Guard Fatally Injured When Struck by a Motor Vehicle - Massachusetts
}

Release Date: January 8, 2013

Investigation: \# 12-MA-010-01
Massachusetts Department of Public Health Occupational Health Surveillance Program

\section{SUMMARY}

On May 23, 2012 a 71-year-old female municipal crossing guard (victim) was fatally injured when she was struck by a motor vehicle while assisting school children in crossing a roadway at an unsignalized pedestrian crosswalk. The victim stepped into the roadway crosswalk and was then struck by a pickup truck. The pickup truck traveled a few feet after striking the victim before coming to a complete stop. Multiple people placed calls for emergency medical services (EMS). EMS and local police arrived within minutes and transported the victim to a local hospital where she died later that same day.

Contributing factors identified in this investigation were that crosswalk markings were in poor condition and of the least visible type of marking and there were no traffic control devices present at the crosswalk location to warn motorists of the crosswalk location.

The Massachusetts FACE Program concluded that to prevent similar occurrences in the future, municipalities should:

- Develop a school route plan that meets the standards set forth in the national Manual on Uniform Traffic Control Devices (MUTCD);

- Consider additional measures, including installing signs and flashing lights, to ensure crosswalks are clearly visible to motorists;

- Ensure that the design of equipment supplied to workers, such as stop paddles, does not prevent employees from using the equipment;

- Provide and ensure that crossing guards are wearing the appropriate personal protective equipment, including American National Standard Institute (ANSI) compliant high-visibility safety apparel, when working along roadways;

- Ensure that crossing guards are provided with initial training and annual refresher trainings; and

- Provide work environments for employees that, at a minimum, meet all relevant Occupational Safety and Health Administration (OSHA) regulations and industry accepted standards of practice per the Department of Labor Standards policy. 


\section{INTRODUCTION}

On May 23, 2012, the Massachusetts FACE Program was alerted by the local media that earlier that same day a female municipal crossing guard had died from injuries sustained when she was struck by a motor vehicle. An investigation was initiated. On June 28, 2012, representatives from the Massachusetts FACE Program and the Massachusetts Department of Labor Standards (DLS) traveled to the employer location, the municipal police department, and met with police department representatives to discuss the incident. The police report and death certificate were reviewed during the course of the investigation. Photographs were taken of the incident location.

\section{EMPLOYER}

The employer is a municipal police department for a Massachusetts city with more than 38,000 residents. The department employs 30 crossing guards that are assigned throughout the city to help students cross roadways on their way to and from the city's seven schools. The city's crossing guards work 7.5 hours per week, which are divided into two shifts per day, Monday through Friday. Each shift is 45 minutes long. The morning shift is 7:30 a.m. to 8:15 a.m. and the afternoon shift is 2:00 p.m. to 2:45 p.m. The city's crossing guards did not have union representation.

\section{WRITTEN SAFETY PROGRAMS AND TRAINING}

At the time of the incident, the department did not have a written safety and health program. It was reported that in the past the department would provide annual 10-minute trainings for the crossing guards in August, before the beginning of the school year, although this training was not held the August before the incident. The department typically provided crossing guards with high visibility vests, rain jackets and stop paddles. It was unknown if the provided equipment was American National Standard Institute (ANSI) compliant.

\section{VICTIM}

The victim was a 71-year-old female municipal worker and had been employed as a crossing guard by the police department for about seven months. The victim was first hired as a spare crossing guard and would fill in at various school crossing locations when needed. Three months before the incident she became a daily crossing guard with a permanent crossing location, which was the incident location. The victim had not been provided the crossing guard training.

\section{INCIDENT LOCATION}

The school closest to the crosswalk that the victim was assigned to was an elementary school for students in kindergarten through eighth grade. This school is located in an urban setting and the school property spans one city block (Figure 1). The roadway in front of the school is a side street that runs east and west and has two travel lanes with one lane for each direction. There is a parallel roadway that is located directly behind the school. This roadway is also a two lane side street that runs east and west with one lane for each direction of traffic. The main roadway, where the incident occurred, is located to the west of the school. This main roadway has two lanes that run north and south with one lane for each travel direction. Parking is allowed along the west side of the southbound travel lane (Figure 2). 
The incident occurred at the unsignalized T-shaped intersection of the main roadway and the side street located at the rear of the school. The intersection has two painted crosswalks. One crosswalk is located across the beginning of the side street and the other is located across the main roadway at the southern side of the intersection. Each crosswalk is made up of two painted parallel lines with no center painted markings (Figure 3). The crosswalks were in poor condition at the time of the incident, the paint was faded and cracked. In contrast, the crosswalks directly in front of the school were made up of two painted parallel lines with painted diagonal center lines. These crosswalks in front of the school were not faded and in good condition (Figure 4).

The speed limit for the main roadway is 30 miles per hour (MPH). The roadway's markings consisted of a white painted fog line along the western edge of the southbound travel lane. This white painted line was approximately eight feet out from the edge of the sidewalk's granite curbing and designates the location for on street parking. The northbound travel lane does not have a white painted fog line and there is no on street parking along this travel lane. The southbound and northbound travel lanes are separated by double yellow parallel divider lines that are painted in the center of the roadway (Figure 4).

Two bus stops are located at the intersection where the incident occurred, one bus stop on either side of the main roadway. The bus stop on the northbound travel lane is located immediately before the intersection and the crosswalk. The bus stop on the southbound travel lane is located across the T-shaped intersection, north of the perpendicular side street (Figure 3). There is a convenience store located in front of this bus stop. The bus stops are designated no parking areas, but during the site visit more than one vehicle had parked in the bus stop to go into the convenience store (Figure 5).

\section{INVESTIGATION}

It was daylight at the time of the incident. The temperature was 66 degrees Fahrenheit and it was mostly cloudy. The victim was wearing a yellow/green fluorescent vest and was using her stop paddle while she was getting ready to cross some students. The victim was standing on the northbound travel lane sidewalk when students walked up to and were standing on the southbound travel lane sidewalk on the opposite side of the main roadway waiting to be crossed. The victim then stepped off of the sidewalk into the crosswalk with her stop paddle raised in the air. The operator of a car traveling south in the southbound lane observed the victim enter the crosswalk and slowed down and stopped before the crosswalk. A pickup truck traveling north in the northbound travel lane did not slow down. As the victim reached the middle of the northbound travel lane she was struck by the oncoming pickup truck. After the pickup truck struck the victim, it traveled a few more feet before coming to a stop, causing the victim to fall onto the roadway. Multiple people placed calls for emergency medical services (EMS). EMS and local police arrived within minutes and transported the victim to a local hospital. The victim died later that same day.

Since the investigation, the police department has implemented multiple changes. The crossing guards have been provided training and new equipment that is ANSI compliant. The crosswalks have been repainted and new permanent signs have been installed to warn motorists of the crosswalk. 


\section{CONTRIBUTING FACTORS}

Occupational injuries and fatalities are often the result of one or more contributing factors or key events in a larger sequence of events that ultimately result in the injury or fatality. The Massachusetts FACE team identified the following contributing factors in this incident.

- Crosswalk markings were the least visible marking pattern.

- Crosswalk markings were in poor condition, faded and cracked.

- No traffic control devices were present at the crosswalk location to warn motorists of the crosswalk location.

\section{CAUSE OF DEATH}

The medical examiner listed the cause of death as blunt force head injuries.

\section{RECOMMENDATIONS/DISCUSSION}

\section{Recommendation \#1: Municipalities should develop a school route plan that meets the standards set forth in the national Manual on Uniform Traffic Control Devices (MUTCD).}

Discussion: A first step in developing a school route plan is to evaluate the area around the school. Municipalities can use school route plans as a way of achieving effective and uniform traffic control throughout the area that will help to reduce confusion among pedestrians, motorists and other roadway users that can contribute to incidents that may cause injuries. When developing a school route plan, participants should include the schools, law enforcement, officials responsible for school pedestrian safety and parent teacher groups. School route plans should consist of a map showing roadways, schools, established school walk routes, and crossings locations and the specific traffic control devices in place at those crossings. ${ }^{1}$

In this case, an evaluation of the routes students walk to get to and from school might have revealed that the crosswalks located at the intersection where the victim was assigned were the least visible type of crosswalk (parallel painted markings) and that the crosswalk paint was in poor condition. Also, the evaluation would have highlighted that this intersection was an unsignalized crossing location and, other than the painted crosswalk, there were no traffic control devices, including pedestrian crossing signs, to warn motorists. An evaluation might have also identified that the city had at least three different types of crosswalks and crosswalk markings in use. Having consistent crosswalk marking and signage will help motorists more quickly identify when they are approaching crosswalks.

The U.S. Department of Transportation's (DOT) Manual on Uniform Traffic Control Devices (MUTCD) sets forth the basic principles that govern the design and usage of traffic control signs and devices. ${ }^{1}$ The MUTCD has a chapter specifically for school crosswalks. Municipalities should follow the MUTCD minimum standards and guidelines to help ensure pedestrian safety as related to crosswalks, proper usage of crosswalk roadway markings, and signage. These standards and guidelines will help determine the appropriate number and location of roadway markings and traffic control devices, including signs. 


\section{Recommendation \#2: Municipalities should consider additional measures, including installing signs and flashing lights, to ensure crosswalks are clearly visible to motorists.}

Discussion: The Massachusetts Highway Department has developed fact sheets providing guidance regarding selected traffic safety and engineering topics for local municipalities. One of these fact sheets entitled Crosswalks includes best practices for crosswalk design, location and visibility. ${ }^{2}$ This document also refers to the MUTCD as a resource.

In this case, as previously stated, prior to the incident there were no traffic control devices present, other than the faded parallel painted lines, to indicate there was a crosswalk. Visually, there was a lot going on in the area of the crosswalk where the incident occurred, including on street parking, convenience store traffic, and bus stops. In order to make the crosswalk, and therefore the students and pedestrians using the crosswalk, more visible to motorists, the following should be addressed:

- Ensure painted crosswalks are highly visible and in good condition. The crosswalk where the victim was struck consisted of two white parallel lines that where faded and in overall poor condition. There are other common markings that can be used for increased crosswalk visibility. These markings include ladder type pattern, with multiple longitudinal lines parallel to traffic flow, or diagonal striping. Crosswalks and other roadway marking should be routinely evaluated to ensure they are not faded and are in good condition.

- Install permanent pedestrian signs, flashing lights, and/or additional street markings at all crosswalk locations. At the incident location there were no signs warning motorists that there was a pedestrian crosswalk. Signs and/or flashing lights should be added, both for the southbound and northbound travel lanes, to give motorists advanced warning of the crosswalk location.

- Provide portable in-street pedestrian crossing signs to crossing guards. The use of portable in-street pedestrian crossing signs during the crossing guards' shifts would give an added warning to motorists of crosswalk locations where students will be crossing the roadway. The crossing guards could put the in-street signs in the center of the roadway at the beginning of their shift and remove it at the end of their shift. This would help keep the signs conspicuous for motorists.

- Prohibit parking and stopping of any motor vehicles within 20 feet of both sides of crosswalks. When vehicles are allowed to park or stop on either side of a crosswalk these vehicles block both the pedestrian's view of oncoming traffic and the motorist's view of the pedestrian trying to enter the crosswalk. "No parking” and "no stopping” signs and roadway markings should be used. Bus stops should also be excluded from this 20 foot zone.

The following are some additional options to help increase the visibility of crosswalks and catch the attention of motorists (not all apply in this incident): 
- Install permanent signs with flashing lights at crosswalks by schools, which would flash only during school commuting times (similar signs are used to indicate reduced-speed zones).

- Install in-pavement roadway warning light systems. The lights for these systems are embedded in the roadway pavement along each side of the crosswalk. ${ }^{3}$

- Trim vegetation in the area to ensure that it is not blocking motorists' views of the crosswalk.

- Use raised crosswalks that bring the roadway within the crosswalk up to the level of the sidewalk. Raised crosswalks improve the visibility of the crosswalk and pedestrian, and act as a speed hump resulting in reduced vehicle speeds. ${ }^{4}$

- In winter months, ensure that crosswalk are free of snow and ice.

\section{Recommendation \#3: Municipalities should ensure that the design of equipment supplied to workers, such as stop paddles, does not prevent employees from using the equipment.}

Discussion: The MUTCD recommends stop paddles as the primary hand signaling device. ${ }^{1}$ In this case, the crossing guards were supplied with stop paddles. These particular stop paddles were heavy and the handles/support sticks were small, making the paddles difficult to use and maneuver. Some of the crossing guards had drilled holes in the stop paddles to try and make them lighter. Municipalities should evaluate the stop paddles and all other equipment currently being used by crossing guards to ensure that the equipment is best suited for the task and the worker using the equipment.

Crossing guards should be encouraged to participate with the equipment evaluation and with selecting new equipment to ensure that the equipment will meet their needs as the users. In this case, two options were identified when discussing the purchasing of new stop paddles: lighter stop paddles with a better handle design, making the paddles easier and less awkward to use and lollipop style stop paddles where one end of the long handle rests on the ground.

In addition, light-emitting diode (LED) stop paddles are available. These stop paddles with flashing LEDs will increase the paddle's visibility range, day or night, which should result in drivers noticing them further in advance than conventional stop paddles. ${ }^{5}$

\section{Recommendation \#4: Municipalities should provide and ensure that crossing guards are wearing the appropriate personal protective equipment, including American National Standard Institute (ANSI) compliant high- visibility safety apparel, when working along roadways.}

Discussion: Crossing guards face many hazards while working. Their work positions them in and around roadways, bringing them in close proximity to motor vehicle traffic usually with no barriers between them and the moving vehicles. Crossing guards should be provided with American National Standard Institute's (ANSI) Class 2 high-visibility safety vests. ${ }^{6}$ In this case, the clothing being worn by the victim reportedly contained reflective material, but the garment class of the clothing was not known. A vest observed during the investigation which was provided to another crossing guard by the department appeared not to be an ANSI Class 2 . 
The Manual on Uniform Traffic Control Devices (MUTCD) states that all workers exposed to the risks of moving roadway traffic or construction equipment should wear high-visibility safety apparel. ${ }^{1}$ The MUTCD refers to the ANSI standard for High-Visibility Safety Apparel (ANSI/ISEA 107-2004). ${ }^{6}$ This standard, published by the International Safety Equipment Association (ISEA), classifies reflective equipment and recommends which class should be worn based on the workers' activities and traffic speed. These classes are:

- Class 3 garments provide the highest level of visibility and are for workers who face serious hazards with high task loads that require attention away from their work where traffic exceeds 50 miles per hour (mph).

- Class 2 garments are intended for use where greater visibility is necessary during inclement weather conditions and when activities occur near roadways where traffic speeds exceed 25 mph.

- Class 1 garments (not for use along highways and streets) are intended for use in activities that permit the wearer's full and undivided attention to approaching traffic. There should be ample separation of the worker from traffic, which should be traveling no faster than 25 miles per hour.

The ANSI standard also states that a competent person designated by the employer should be responsible for selecting the appropriate class of garment for the workers. A competent person, as defined by the Occupational Safety and Health Administration (OSHA), is a person who, through training or knowledge, is capable of identifying existing and predictable hazards in the surroundings or working conditions that are unsanitary, hazardous, or dangerous to employees, and who has authorization to take prompt corrective measures to eliminate them. Employers should routinely evaluate the high-visibility safety apparel to ensure that the apparel is in good condition. Also employers should ensure that workers are wearing the provided high-visibility safety apparel.

\section{Recommendation \#5: Municipalities should ensure that crossing guards are provided with initial training and annual refreshers.}

Discussion: Reportedly there was a 10-minute annual training that the police department provided to the crossing guards each August, before the beginning of the school year. This training was not held the August before the incident occurred. Municipalities should develop formal classroom training for crossing guards that includes verbal instruction, written materials and videos, and pre- and post-tests. The classroom training should be followed by on-the-job training where crossing guards will demonstrate their ability to perform the job. Then crossing guards should be provided with annual refresher trainings.

Training materials should be routinely reviewed and updated. This will ensure that all trainings are updated to include newly recognized hazards and newly implemented equipment. Crossing guards should be included in the process of reviewing and updating the training materials. In addition, a review of the materials and training should be performed after an incident or nearmiss incident. Mandatory trainings, held during normal working hours or not, should be paid time for attendees. 


\section{Recommendation \#6: Municipalities should provide work environments for employees that, at a minimum, meet all relevant Occupational Safety and Health Administration (OSHA) regulations and industry accepted standards of practice per the Department of Labor Standards policy.}

Discussion: The federal Occupational Safety and Health Act requires private sector employers to provide workplaces that are free from recognized hazards likely to cause death or serious physical harm to employees. While private sector employees are covered by federal OSHA, public sector employees in Massachusetts are not. The Massachusetts Department of Labor Standards (DLS), in accordance with Chapter 149 Section 6, is charged with inspecting public sector workplaces in Massachusetts and determining what procedures and practices are required to protect workers. ${ }^{7}$ As a matter of policy, DLS references OSHA Standards, standards set forth in the MUTCD, as well as other consensus standards such as ANSI, in determining whether proper procedures are being followed to protect workers.

Municipalities should work together to help ensure that crossing guards are being provided workplaces that are free from recognized hazards likely to cause death or serious physical harm. In this case, the police department, as the employer, has the greatest responsibility to ensure the safety of crossing guards, but schools and school departments also have important responsibilities to ensure the safety of the crossing guards, which in turn will help ensure the safety of the students while getting to and from their schools.

Schools and school departments can help ensure that parents and others dropping off and picking up students at the schools are not creating serious traffic hazards. The American Automobile Association (AAA) has developed a fact sheet on this topic and refers to some hazards that can be created when dropping off and picking up students at school. These include double-parking, blocking traffic, and stopping in a crosswalk, all of which may block visibility for crossing guards, students, and other motorists. (www.state.nj.us/health/surv/documents/aaa_parents.pdf)

Police departments can help ensure that motorists are obeying relevant Massachusetts general laws that will help keep the crossing guards, students and other pedestrians safe as they walk across roadways. This would include, but not be limited to, ensuring motorists are operating their vehicles within the speed limit (Chapter 90, Section 17 Speed limits), and that motorists yield the right of way to pedestrians crossing within crosswalks, including stopping if needed. Motorists who do not yield to pedestrians in crosswalks can be fined up to \$200 (Chapter 89, Section 11 Marked crosswalks; yielding right of way to pedestrians; penalty).

\section{ADDITIONAL RESOURCES}

MA FACE Safety Alert: Protect the Crossing Guards that Protect Our Children. October 2012. www.mass.gov/eohhs/docs/dph/occupational-health/face-facts/crossing-guards-legal.pdf

NJ DOH. Adult School Crossing Guard web page. www.nj.gov/health/surv/crossing_guards.shtml 


\section{REFERENCES}

1. US DOT 2009. Manual on Uniform Traffic Control Devices (MUTCD), 2009 Edition, U.S. Department of Transportation Federal Highway Administration.

http://mutcd.fhwa.dot.gov/pdfs/2009/part7.pdf. Date accessed: 8/29/2012.

2. Massachusetts Highway Department 2008. Crosswalks: MA Traffic Safety Toolbox Series. www.mhd.state.ma.us/safetytoolbox/downloads/Crosswalks.pdf. Date accessed: 8/29/2012.

3. Institute of Transportation Engineers. Institute of Transportation Engineers Pedestrian Award Program 2003. City of Glendale, California. www.ite.org/activeliving/files/C-2-C_ppa002.pdf. Date accessed: 8/29/2012.

4. Massachusetts General Laws, Chapter 89: Section 11. Marked crosswalks; yielding right of way to pedestrians; penalty. www.mass.gov/legis/laws/mgl/89-11.htm. Date accessed: 8/29/2012.

5. ATSSA 2006. Putting Safety in the Safe Routes to School Program. A Schools Administrator Guide. American Traffic Safety Services Association. www.atssa.com/galleries/defaultfile/SRTSAdminGuide.pdf. Date accessed: 8/29/2012.

6. ANSI/ISEA 2004. American National Standard for high-visibility safety apparel. New York, NY: American National Standards Institute, ANSI/ISEA 107 -2004.

7. Massachusetts General Laws, Chapter 149: Section 6. Safety devices and means to prevent accidents and diseases generally; fees for structural painting.

\section{Figure 1 - Aerial view of the school and surrounding roadways}

The $\mathrm{X}$ marks the location of the victim and the crosswalk where she was struck. The arrow shows the walking route to the rear entrance of the school.

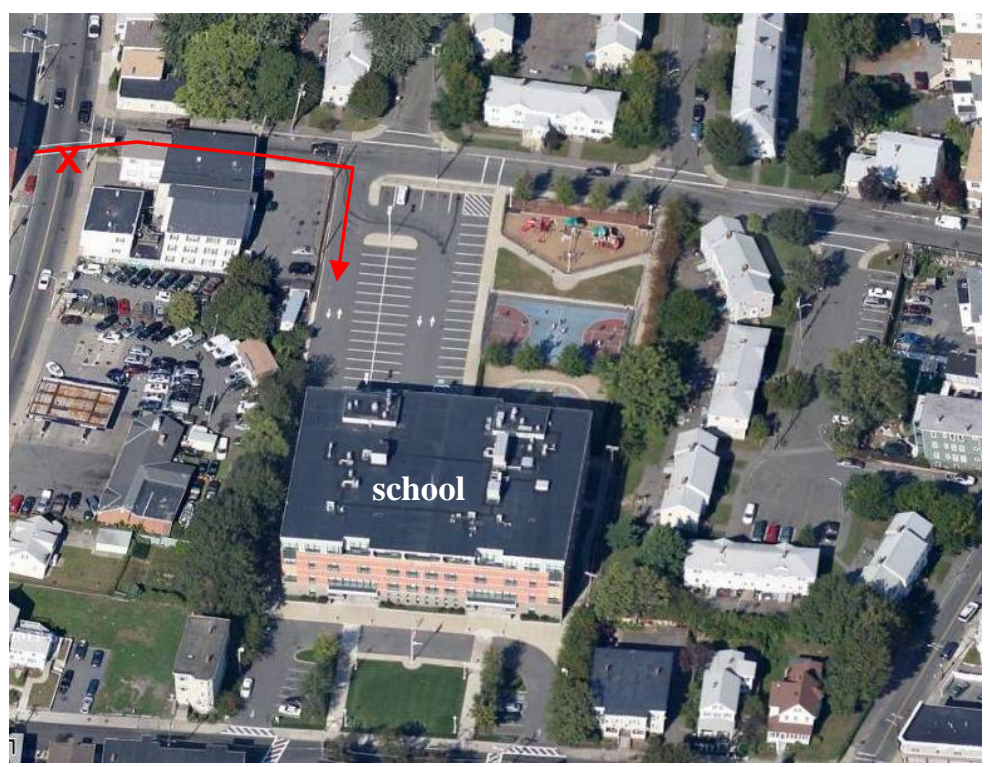


Figure 2 - View of the main roadway heading north towards the intersection

Arrow points to the crosswalk where the victim was struck and direction of travel and approximate location of the truck involved.

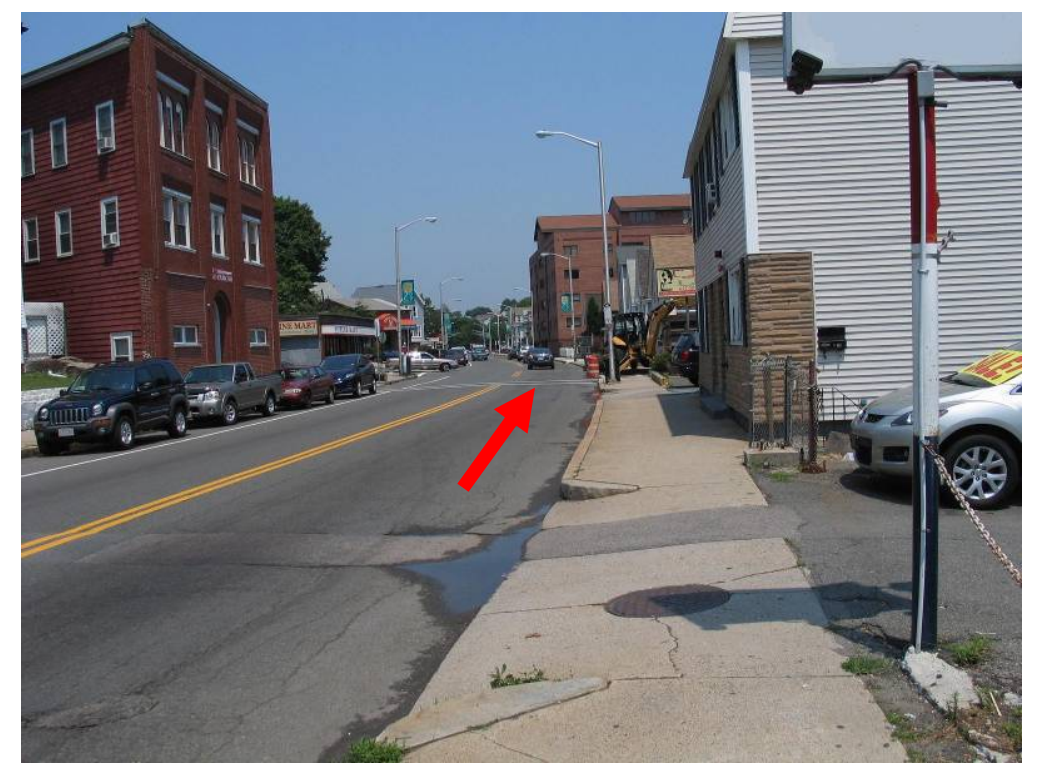

Figure 3 - Aerial view of the intersection where the incident occurred.

Red arrow points to the crosswalk where the victim was struck and the direction and approximate location of the truck involved.

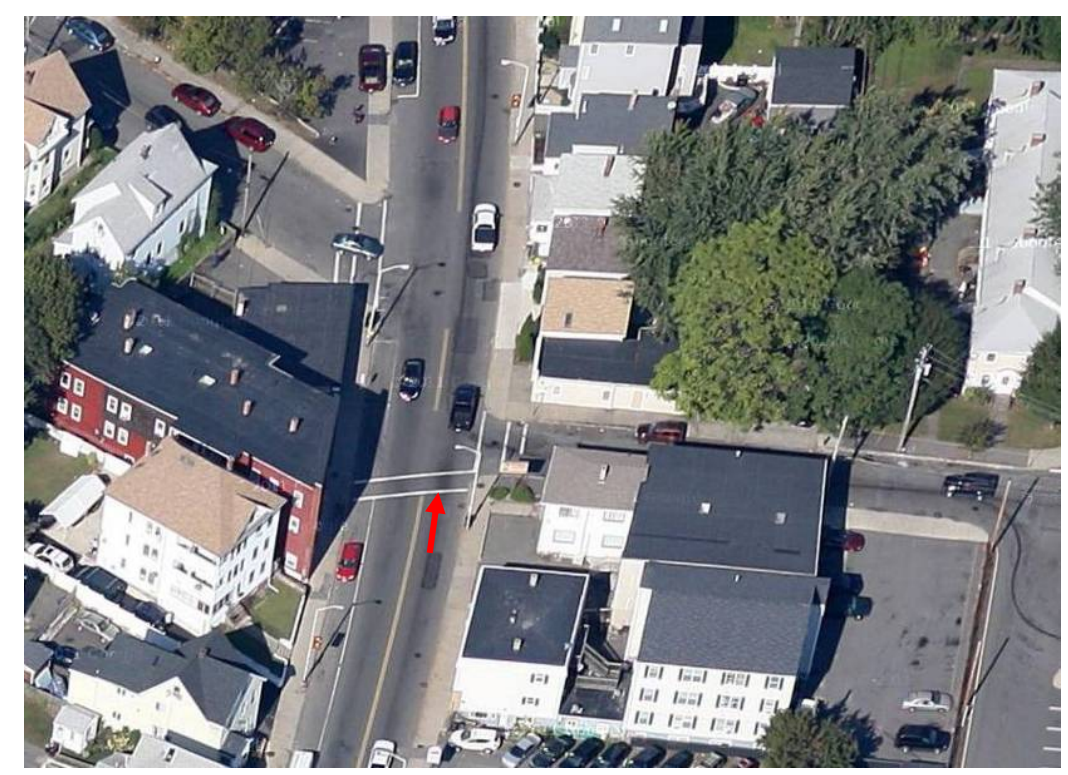


Figure 4 - Crosswalk markings located in front of the school

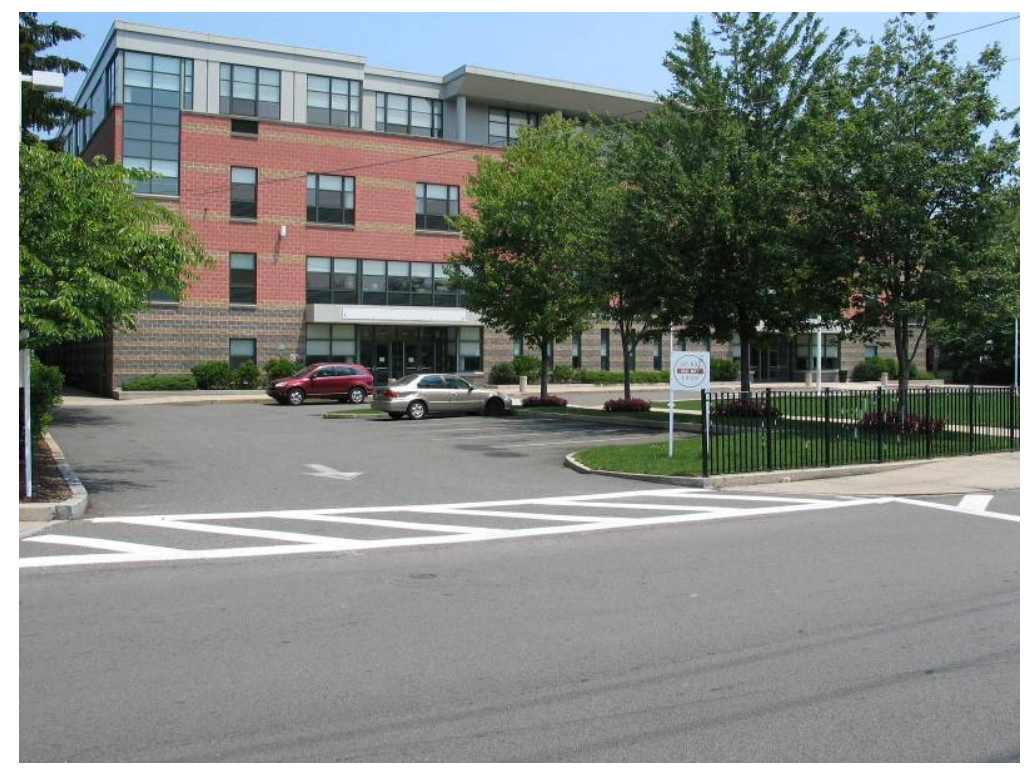

Figure 5 - Incident location with vehicles parked on both sides of the crosswalk

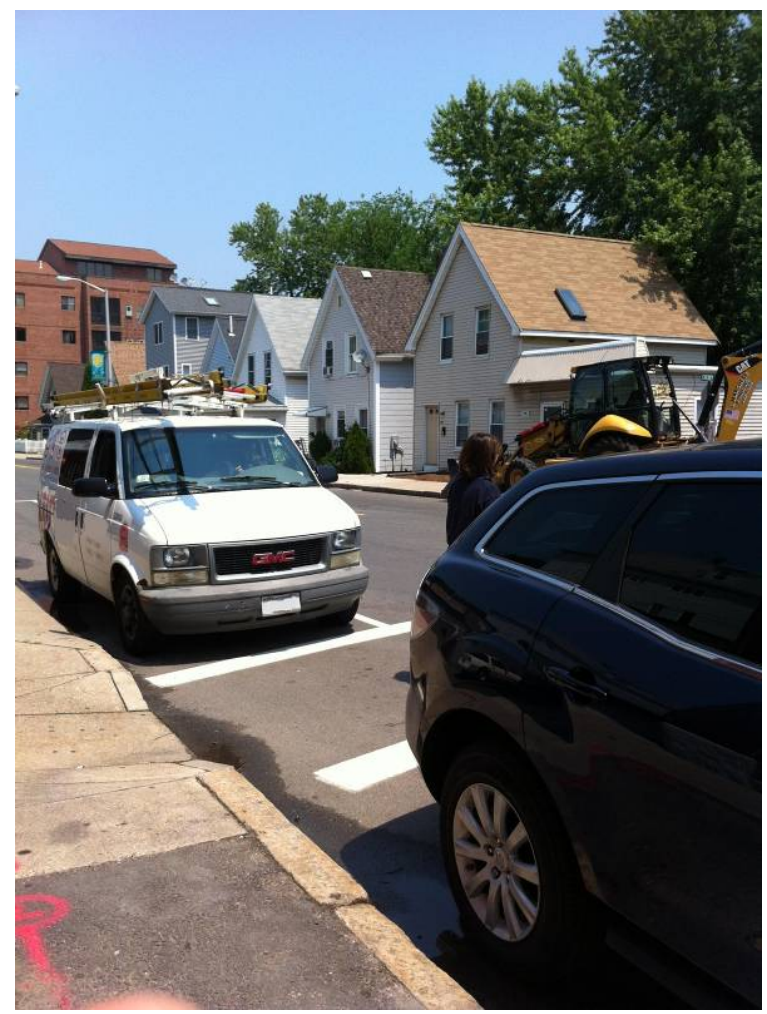


Michael A. Fiore, MS, Director

Massachusetts FACE Program

Occupational Health Surveillance Program

Massachusetts Department of Public Health
Letitia Davis, Sc.D., Ed.M., Director

Occupational Health Surveillance Program

Massachusetts Department of Public Health

$* * * * * * * * * * * * * * * * * * * * * * * * * * * * * * * * * * * * * * * * * * * * * * * * * * * * * * * * * * * * * * * * * * * * * * * * * * * * * *$

\section{FATALITY ASSESSMENT AND CONTROL EVALUATION PROGRAM}

The Massachusetts Department of Public Health, in cooperation with the National Institute for Occupational Safety and Health (NIOSH), conducts investigations on the causes of work-related fatalities. The goal of this program, known as Massachusetts Fatality Assessment and Control Evaluation (Massachusetts FACE) is to prevent future fatal workplace injuries. Massachusetts FACE aims to achieve this goal by identifying and studying the risk factors that contribute to workplace fatalities, by recommending intervention strategies, and by disseminating prevention information to employers and employees.

Massachusetts FACE also collaborates with engineering and work environment faculty at the University of Massachusetts at Lowell to identify technological solutions to the hazards associated with workplace fatalities.

NIOSH funded state-based FACE Programs currently include: California, Iowa, Kentucky, Massachusetts, Michigan, New Jersey, New York, Oregon, and Washington.

Additional information regarding this report is available from:

Occupational Health Surveillance Program

Massachusetts Department of Public Health

250 Washington Street, 6th floor

Boston, Massachusetts 02108-4619

(617) 624-5627

\section{$\underline{\text { Evaluate this report }}$}

We would appreciate your feedback on these reports so we may continue to improve the MA FACE project and our investigation reports. A feedback form can be found at:

www.mass.gov/eohhs/docs/dph/occupational-health/report-evaluation.doc

The completed form may be returned by fax to (617) 624-5676, by mail to FACE, 250 Washington

Street, $6^{\text {th }}$ Floor, Boston, MA 02108, or by email to ma.face@state.ma.us. 